\title{
As ferramentas tecnológicas nos métodos de ensino-aprendizagem: uma revisão de literatura
}

O processo de ensino-aprendizagem vem se modificando e modernizando cada vez mais nos dias atuais, o uso das novas ferramentas tecnológicas proporciona novas abordagens para a educação contemporânea, desse modo o presente estudo tem como objetivo abordar os impactos positivos que a tecnologia tem no desenvolvimento dos métodos de ensino-aprendizagem, a partir de uma revisão da literatura. Os estudos publicados evidenciam que através do uso da tecnologia se pode despertar maior interesse por partes de estudantes para o aprendizado de novos conteúdos. Estas ferramentas devem ser planejadas pedagogicamente e economicamente para que os resultados possam ser positivos nos processos de ensino-aprendizagem.

Palavras-chave: Educação; Tecnologia; Ensino-Aprendizagem.

\section{Technological tools in teaching-learning methods: a literature review}

The teaching-learning process has been changing and modernizing more and more nowadays, the use of new technological tools provides new approaches for contemporary education, so this study aims to address the positive impacts that technology has on development of teaching-learning methods based on a literature review. Published studies show that through the use of technology, greater interest can be aroused by parts of students to learn new content. These tools must be planned pedagogically and economically so that the results can be positive in the teaching-learning processes.

Keywords: Education; Technology; Teaching-Learning.

Topic: Tecnologia, Educomunicação e Cibercultura

Reviewed anonymously in the process of blind peer.
Received: $15 / 03 / 2020$

Approved: 09/05/2020
Eduardo Victo Lima Aureliano (iD)

Centro Universitário Vale do Salgado, Brasil

http://lattes.cnpq.br/2261087801794706

eduardoaureliano96@gmail.com

Antoniel dos Santos Gomes Filho (iD

Centro Universitário Vale do Salgado, Brasil

http://lattes.cnpq.br/9563145614494252

http://orcid.org/0000-0003-2230-4315

antonielsantos@univs.edu.br

Maria Erilucia Cruz Macêdo (iD)

Centro Universitário Vale do Salgado, Brasil

http://lattes.cnpq.br/4333538235010417

mariaerilucia@hotmail.com
Otácio Pereira Gomes (iD)

Centro Universitário Vale do Salgado, Brasil

http://lattes.cnpq.br/3296784496379104

otaciopereira@univs.edu.br
Referencing this:

AURELIANO, E. V. L.; GOMES FILHO, A. S.; MACÊDO, M. E. C.; GOMES, O. P.. As ferramentas tecnológicas nos métodos de ensinoaprendizagem: uma revisão de literatura. Educationis, v.8, n.2, p.8-18, 2020. DOI: http://doi.org/10.6008/CBPC2318-3047.2020.002.0002 


\section{INTRODUÇÃO}

A tecnologia vem revolucionado os métodos educacionais e as próprias instituições de ensino como um todo. Ao longo do tempo as novas tecnologias que vem surgindo são usadas cada vez mais na educação como apoio aos métodos já existentes e proporcionando a possibilidade do surgimento de novos métodos cada vez mais adequados as novas gerações e facilitando também o aprendizado das anteriores.

Corroborando com os autores Quintana et al. (2018) ao usar tecnologias da informação em cursos presenciais, utilizando-as como tecnologias didáticas, pode-se apresentar uma forma moderna de se contribuir com o processo de aprendizagem, que pode se desenvolver com atividades na sala de aula ou fora desta utilizando os recursos que a tecnologia pode oferecer.

As diferentes tecnologias existentes atualmente podem ser usadas de diversas maneiras para criar os mais variados métodos educacionais, cada um destes tendo uma experiência completamente diferente um do outro, e isto possibilita que os diferentes tipos de estudantes de diferentes idades, gêneros, tradições e situações socioeconômicas consigam se familiarizar com algum destes métodos de ensino e dessa forma conseguir absorver o conteúdo de forma mais prática e intuitiva de acordo com sua forma de aprendizagem e interesses, podendo até mesmo buscar por si próprio o conhecimento que o mesmo pretende e precisar adquirir (QUINTANA et al., 2018).

Este estudo tem por objetivo abordar os impactos positivos que a tecnologia tem no desenvolvimento dos métodos de ensino-aprendizagem a partir de uma revisão da literatura, dessa forma os objetivos específicos desta pesquisa são de analisar quais são estes resultados, identificar como cada um dos métodos analisados teve influência sobre a aprendizagem e se é ou não viável a aplicabilidade de alguns destes métodos a partir de uma revisão de literatura.

A realização deste trabalho justifica-se pois cada vez mais as novas gerações em quaisquer níveis de ensino fazem parte de uma era onde tudo e todos estão conectados e em grande parte por já haver vivencia com as tecnologias a maioria já tem uma certa facilidade e conforto ao usa-las seja no cotidiano ou mesmo em sala de aula. Para Dias et al. (2013), sabendo-se que com o tempo o setor educacional se modela aos novos tempos e as novas tecnologias vão cada vez mais sendo utilizadas é necessário estudar os comportamentos dos educadores e educandos diante da adoção destes métodos e quais são os fatores que os fazem ter êxito ou não em seus resultados.

A metodologia utilizada para este trabalho foi uma revisão de literatura de vários artigos, este método visa de forma geral analisar os resultados de estudos já realizados sobre um certo tema. Tendo como base os resultados destes estudos previamente analisados é possível realizar uma busca de um consenso geral entre estes ou avaliar o que pode causar divergências em seus resultados. Para as autoras Lozada et al. (2018) na metodologia cientifica a leitura é um dos passos mais decisivos para a realização de um estudo pois é por meio da leitura que a maioria dos conhecimentos são obtidos e dessa forma é possível aprofundar o conhecimento em determinados campos seja este cultural ou cientifico, além de ser imprescindível em todo o tipo de investigação cientifica pois permite que sejam obtidas informações básicas e especificas sobre o 
que se estuda.

\section{METODOLOGIA}

\section{Tecnologia na educação}

Para esclarecer relacionamento do uso da tecnologia com o desenvolvimento de novos métodos de ensino-aprendizagem é preciso saber o que já foi realizado e testado de diversas maneiras e como isso pode contribuir na aprendizagem de forma positiva.

Visando saber que efeitos algumas ferramentas tecnológicas podem ter se bem utilizadas em sala de aula os autores Quintana et al. (2018) realizaram um experimento em uma turma de primeiro semestre do curso de Ciências Contábeis, neste estudo a turma foi dividida aleatoriamente (sorteio) em dois grupos de chamando-os de grupo de controle (GC) que teriam aulas normais e grupo de tratamento (GT) onde além das aulas tradicionais seriam usadas as ferramentas tecnológicas de chat e fóruns online, além disso para se ter um bom parâmetro de resultados em cada um dos grupo foi aplicado uma prova previamente para medir o desempenho prévio e a cada bimestre os grupos seriam invertidos se aplicando outra prova para novamente ter precisão nos resultados. Os resultados da pesquisa em questão serão abordados na próxima sessão.

Para Dias et al. (2013) aqueles que estão acostumados ao uso da tecnologia no geral costumam se adaptar melhor ao uso de novos métodos que a utilizam e geram maiores expectativas de resultados com estes tipos de método já que geralmente este grupo de pessoas pode se considerar inovador quando a questão é superar as possíveis complexidades de uso de uma nova ferramenta tecnológica.

Outra tecnologia que vem se popularizando bastante nos novos tempos são os E-books ou livros digitais, estes podem ser lidos em qualquer lugar e a qualquer hora contato que se tenha pelo menos um smartphone em mãos. Segundo Martins et al. (2018), os e-books são simplesmente a versão moderna dos livros, que mesmo em papel são uma tecnologia de leitura e transmissão de conhecimento construída na antiguidade pela civilização humana. Ainda para estes autores o modo como boa parte dos setores da sociedade se organizam assim como o modo que armazenamos e transferindo informações está mudando dia após dia e, dessa forma, muitas das atividades de hoje podem acabar deixando de existir com o tempo a medida em que os e-books vem ganhando mais espaço e utilidade em nosso cotidiano.

Também pode-se destacar como ferramenta tecnológica que vem crescendo na utilização pedagógica são os jogos eletrônicos, conforme Fernandes (2010) ao introduzir computadores na educação abriu-se um leque de possibilidades para novas ferramentas de auxílio a aprendizagem e entre essas ferramentas vale a pena destacar os jogos educacionais que podem ser usados em qualquer disciplina para transmitir diferentes tipos de conhecimentos. Ainda segundo o autor para as crianças e adolescentes é muito mais prazeroso aprender jogando pois nos dias atuais os jogos na maioria das vezes já fazem parte dos seus cotidianos e para sua correta utilização em sala de aula apenas é necessária uma prévia avaliação pedagógica do jogo em questão para saber a sua eficiência em sala de aula. 
Um modelo educacional que surgiu a partir do uso da tecnologia moderna é a educação a distância, neste modelo o aluno pode cursar suas disciplinas sem precisar estar presente em um local fixo e nem estar junto com o professor para poder estudar, este método está cada vez mais popular nos dias atuais e Ferreira et al. (2017) explicam que atualmente as pessoas tem muitas dificuldades logísticas de mobilidade urbana além da distância que muitas vezes podem ser um fator impeditivo para a participação de alunos no método de ensino presencial, além disso há também alguns outros fatores como a dinâmica em seus cotidianos e horários e as atribuições que os indivíduos tem a cumprir em suas vidas particulares.

As autoras ainda destacam que nesse modelo educacional as mudanças nos métodos de ensinoaprendizagem foram radicais se comparado com o modelo presencial pois segundo as mesmas a produção do material didático propriamente dito pode padronizar o ensino de forma quantitativa, porém a relação da aprendizagem em si não é padronizada e sim individualizada uma vez que está exige uma perspectiva de relações sociais e dessa forma se não há um espaço físico para a reunião entre professor e estudantes cada indivíduo terá a construção de seus conhecimentos definida a partir de seus próprios parâmetros e métodos individuais.

\section{DISCUSSÃO TEÓRICA}

\section{Experiências na educação com utilização de tecnologias}

Para se ter certeza dos possíveis resultados da utilização em sala de aula de ferramentas tecnológicas é preciso principalmente testa-las na prática e analisar quais foram estes resultados e se foram positivos ou negativos para aqueles que mais precisam de bons resultados, ou seja, os estudantes. Os autores Quintana et al. (2018) em um estudo na realizado cidade de Blumenau/SC desenvolveram um método de uso dessas ferramentas e resolveram colocá-lo em prática em uma sala de aula de um curso de ensino superior em uma turma de primeiro semestre de Ciências Contábeis, como explicado na sessão anterior sobre o método que estes autores desenvolveram a turma foi dividida em dois grupos (GT e GC), o primeiro teve aulas normais e utilizou também ferramentas online de chat e fórum, já o segundo grupo apenas teve aulas presenciais.

Para que este experimente tivesse os resultados mais precisos possíveis os autores criaram algumas regras para sua aplicabilidade, primeiramente no primeiro dia de aula do semestre foi aplicada uma avaliação inicial e um questionário sobre o perfil destes alunos (idade, gênero, se trabalham e se tem ou não curso técnico), ao final do primeiro bimestre foi aplicada uma prova para ambos os grupos para avaliar o resultado da evolução do aprendizagem e após isso os grupo foram invertidos, ou seja, os integrantes do GT passaram a fazer parte do GC e vice-versa, ao final do 20 bimestre foi aplicada uma outra prova para verificar novamente a evolução do desempenho do ambos os grupos. Analisaremos o resultado do experimento deste autor para verificar os resultados (QUINTANA et al., 2018).

No primeiro bimestre do experimento o GT ficou com 34 membros e o GC com 32 e durante a aplicação da primeira prova para saber o conhecimento prévio dos participantes, e os resultados foram que a média de notas do GT foi de 3,0 pontos enquanto a do GC foi de 4,1 pontos, sendo assim vê-se que 
previamente há uma certa diferença clara no desempenho dos grupos, buscando uma hipótese sobre quais os principais motivos desta diferença de desempenho os autores correlacionaram os alunos que trabalham ou não e que tem curso técnico ou não e descobriram que os estudantes que trabalham obtiveram, em média um desempenho superior aos que não trabalham e o GC tinha 22 membros contra 18 do GT além de que haviam 14 membros que não tem curso técnico e não trabalham no GT contra 6 do GC e estes foram os que obtiveram o menor desempenho (QUINTANA et al., 2018).

Ao começar a utilização das ferramentas a primeira utilizada pelos autores foi o chat onde os mesmos destacam que através dessa ferramenta os alunos ler as informações postadas por si mesmos ou por seus colegas além de interagir em todo real com todos incluindo o professor, este por sua vez sempre abordava os alunos neste chat com alguma questão para gerar discussão sobre esta questão e também atua como agente mediador tentando orientar os discentes (QUINTANA et al., 2018).

Também foi utilizada a ferramenta de fórum online onde os autores destacam que o professor pode primeiramente postar uma questão e os alunos podem pesquisar e refletir sobre a resposta, além de também poder acompanhar as respostas de seus colegas e ajuda-los na pesquisas e reflexões sobre a questão apresentada (QUINTANA et al., 2018).

Após o fim do primeiro bimestre foram novamente aplicadas avaliações em ambos os grupos e foi verificado que dessa vez o GT obteve uma média de 6,74 pontos, no começo do bimestre haviam 34 alunos, porém ao fim 3 desistiram, este grupo ficando assim com 31 alunos e a média anterior ao desconsiderar os desistentes seria de 2,77 pontos, ou seja, houve uma variação de 3,97 pontos. Já no GC a nota média aumentou para 6,59 pontos e antes era de 3,90 pontos (considerando desistências). Em ambos os grupos o desempenho aumentou sendo que o GT teve um amento de 53\% enquanto o de 31\% (QUINTANA et al., 2018).

No segundo bimestre os grupos foram invertidos e agora o que antes era o GT seria o GC e vice-versa, e então as etapas realizadas no primeiro bimestre foram repetidas, sendo que nas aulas iniciais do 2 bimestre também foi aplicada uma avaliação com conteúdo que seriam ministrados no decorrer do bimestre para novamente quantificar o conhecimento prévio dos alunos sobre este conteúdo. Dessa vez foi verificado que o GT obteve uma média de 1,2 pontos e o GC de 1,3 pontos e em função de desistências cada grupo ficou com 30 alunos. A diferença entre as notas das provas iniciais do 10 e 20 bimestre podem ter sido causadas pois no 2 ㅇo a aplicado um conteúdo mais avançado que os alunos em sua maioria ainda não tinha conhecimento (QUINTANA et al., 2018).

Ao final do $2 \circ$ bimestre foram novamente aplicadas avaliações onde o resultado foi que a nota do GT foi de 0,92 pontos (devido a 5 desistências) para 6,17 pontos e a do GC de 1,54 pontos (devido a 6 desistências) para 7,27 pontos. Os autores notaram que os estudantes que tinham até 25 anos tiveram um crescimento em seu desempenho maior quando estiveram no GT já os estudantes com mais de 30 que fazem parte do GC anos tiveram uma média maior além de que os outros alunos no geral e $11 \%$ maior do que os da mesma categoria de idade que estiveram no GT, ou seja os autores notaram que para os estudantes mais jovens quando a tecnologia é utilizada a variação positiva é maior do que para os estudantes mais velhos 
(QUINTANA et al., 2018).

Já no estudo realizado pelas autoras Guarda e Goulart (2018) em Brasília/DF, foi realizado um experimento com alunos do 5 ㅇ e 6 o anos do ensino fundamental de uma escola particular do DF, os alunos que participaram do experimento tem idades variantes entre 9 e 11 anos. Ao todo contribuíram com o experimento cerca de 35 alunos do 5 ㅇ ano e 18 do 6 o ano totalizando 53 alunos participantes. Neste estudo as autoras propõem utilizar alguns jogos lúdicos em forma de computação desplugada para despertar o interesse dos alunos em lógica de programação e assim trabalhar com o raciocínio lógico-matemático dos mesmos assim melhorando seu desempenho nas ciências exatas principalmente nas disciplinas de matemática e ciências, para tal fim as autoras elaboraram três jogos lúdicos chamados de CriptoLAB, LightBot Logicamente e Circuito 4 Desafios, cada um destes teve por objetivo trabalhar algumas competências lógicas dos alunos participantes.

Começando com o CriptoLAB que é um jogo que tem como objetivo estimular o desenvolvimento do raciocínio lógico e computacional através da abordagem do uso dos conceitos de criptografia e sequencias lógicas de forma estruturada e tudo em forma de computação desplugada. Este jogo foi estruturado em cinco partes sendo elas: sortear e responder uma questão, decodificar uma mensagem, procurar uma ficha e montar partes de um esquema lógico baseado na linguagem de programação do aplicativo Scratch do MIT e apenas ao completar com sucesso as quatro primeiras partes a quinta poderia ser concluída que seria travessia de um labirinto desenhado numa folha de papel A4 que poderia ser completado se a sequência lógica que foi montada pelos participantes estiver correta (GUARDA et al., 2018).

Na primeira etapa do jogo os alunos sorteiam uma questão de múltipla escolha de raciocínio lógicomatemático alinhada com os conhecimentos acadêmicos de estudantes de 5o e 6o anos, assim que respondida uma questão, esta questão era corrigida e caso a resposta estivesse correta era desbloqueada a próxima etapa. A segunda fase do jogo consistia em decodificar uma mensagem e o conteúdo dessa mensagem revelaria qual funcionário estaria com uma ficha que desbloquearia a próxima etapa do jogo. Ao chegar na terceira etapa um estudante do grupo apelidado de 'corredor' teria que procurar o funcionário que está com a ficha para em seguida poder troca-la por um envelope que estaria com os trechos de código que permitem a passagem pelo labirinto. A quarta etapa se refere a montagem dos trechos de código de forma estruturada de maneira que fosse possível atravessar o labirinto e a quinta fase do jogo só seria desbloqueado se os trechos estivessem montados de forma correta. Essas etapas repetiram-se quatro vezes alterando-se apenas o conteúdo em geral até que o código estivesse completo e ao final os grupos receberam uma folha com o labirinto e uma tabela na qual deveria ser escrita a solução do problema, no qual deveria ser descrita quantas vezes e quais as teclas que deveriam ser acionadas assim simulando como se a atividade fosse realizada no computador (GUARDA et al., 2018).

O segundo jogo proposto foi o LightBot Logicamente que foi inspirado no jogo digital educativo LightBot onde esse jogo teve por objetivo induzir o conhecimento de raciocínio lógico como o ensino de comandos básicos de programação através do uso de comandos que fazem referência direta a algoritmos que exploram estruturas sequenciais, de seleção, de repetição e funções sem necessitar da compreensão de 
escrita de pseudocódigos. O jogo contou com um 'robô' que tinha a função de realizar um percurso dentro de um labirinto com um determinado número e jogadas, o jogador teria um bloco de ações principal e dois blocos de ações secundarias, sendo o principal chamado de Main e os secundários de PROC1 e PROC2 (P1 e P2), no jogo original o robô poderia executar as ações: andar para frente, virar à direita, virar à esquerda, pular, acender a luz e acionar procedimentos repetitivos que seriam os comandos escritos nos bloco P1 e P2 que funcionariam em forma de funções. Essas ações deveriam ser informadas no bloco Main utilizando os comandos para montar a sequência lógica a ser executada. Na versão lúdica montada pelas autoras foram utilizados dois quadros para que os estudassem pudessem recolher e selecionar os blocos para realizar a montagem de sequencias lógicas e como regra o bloco principal só poderia ter até 12 comandos e os blocos P1 e P2 poderiam ter 8 comandos cada para tornar mais completa a solução e além disso a fim de estimular o aprendizado em matemática dos alunos o comando de acender a luz que existe no jogo original foi substituído por uma ação na qual deveria ser respondida uma questão da Olimpíada Brasileira de Matemática referente ao Ensino Fundamental (OBM) (GUARDA et al., 2018).

O jogo contou com a divisão da turma em grupos de quatro integrantes e todos tiveram 65 minutos para realizar a atividade, nesse tempo as equipes tiveram que encontrar uma solução para o tabuleiro e após isso responder questões da OBM. O grupo que conseguisse terminar primeiro o tabuleiro e responder as questões no menor tempo ganharia o jogo e em caso de empate foi utilizado o critério do grupo que conseguiu responder o maior número de questões (GUARDA et al., 2018).

Por último temos o jogo que foi chamado pelas autoras de Circuito 4 Desafios neste jogo a sala foi dividida em 4 áreas distintas cada uma tendo uma cor e número para fins de organização do ambiente, privacidade dos grupos e também não prejudicar a concentração dos estudantes. Cada uma das áreas teve uma atividade diferente que foi acompanhada por um monitor que poderia auxiliar os grupos em casos de dúvidas, esses monitores também serviram para monitoramento do desempenho dos estudantes assim como o desenvolvimento da atividade, assim conseguindo observar sua efetividade e a capacidade de abstração dos estudantes. Na dinâmica que foi definida o tempo total para a execução da atividade foi de 100 minutos e cada grupo teve um líder que tinha a função de receber as medalhas que valiam uma certa pontuação e as equipes tinham um tempo de 20 minutos para a resolução da atividade proposta em cada área do circuito, ao final desse tempo independente do termino ou não da atividade a equipe avançaria para a próxima área em sentido horário (GUARDA et al., 2018).

Após a conclusão da atividade proposta em uma área do líder recebia uma medalha que valeria 400 pontos e as equipes poderiam receber algumas penalizações e irem perdendo pontos com o tempo, para isso foram definidos pelas autoras alguns critérios sendo eles: equipes que fizessem muito barulho perderiam 50 pontos, equipes que copiassem as outras perderiam 100 pontos e caso houvesse um empate seria realizada uma prova surpresa como critério de desempate (GUARDA et al., 2018).

Quanto ao desafio propriamente dito as atividades que estavam no circuito eram os seguintes: $\mathrm{Na}$ área 1 havia o desafio do Tangram que é um jogo inspirado em antigos quebra-cabeças chineses, composto por sete peças geométricas, sendo elas dois triângulos isósceles grandes, dois pequenos e um médio, um 
quadrado e por fim um paralelogramo. Esse quebra cabeça formar várias figuras como animais, pessoas objetos ou figuras geométricas, assim trabalhando a abstração, reconhecimento e manipulação de figuras geométricas; Na área 2 foi realizado o desafio Resta 1 que é um jogo inglês formado por um tabuleiro com um total de 33 casas em forma de cruz onde 32 dessas casas estão ocupadas por peças do jogo e a casa central ficando vazia, esse jogo tem como objetivo retirar peças realizando movimento parecidos com o jogo de damas de forma que no final deve sobrar apenas uma peça na casa central que começou vazia; Na área 3 os estudantes realizaram o desafio da Expressão numérica que tinha o objetivo de desenvolver a habilidade de solucionar um problema através da técnica de decomposição (dividir um problema em partes menores), e para isso foi aplicado no desafio uma expressão numérica; Na área 4 o desafio apresentou um problema de lógica aos estudantes que foi o seguinte: “Um fazendeiro quer levar o leão, o burro e o feno para o outro lado do rio. Porém, ele não pode levar o leão junto com o burro, pois este o comeria. Nem o burro com o feno", após os alunos conseguiram a solução para este problema era entregue aos mesmos um papel que os estudantes deveriam escrever um algoritmo para representar a solução do problema (GUARDA et al., 2018).

As autoras ainda destacam algumas das competências que foram trabalhadas com os alunos em cada um dos jogos realizados, que no CriptoLAB foi desenvolvido a Abstração, Decomposição, Coleta de Dados, Análise de Dados e Construção de Algoritmo; No LightBot Logicamente foram trabalhas as competências de Automação, Decomposição, Coleta de Dados, Análise de Dados e Construção de Algoritmo; No Circuito 4 Desafios foram trabalhadas as competências de Abstração, Análise de Dados, Construção de Algoritmo, Paralelismo, Decomposição e Coleta de Dados (GUARDA et al., 2018).

Para que fossem analisados os resultados do experimento a escola em que o estudo foi realizado forneceu os boletins dos estudantes que participaram assim sendo possível realizar um diagnóstico da evolução das notas das turmas de 5 e 6ㅇanos nas disciplinas de Matemática e Ciências (disciplinas da área de Ciências Exatas), as notas averiguaras estão distribuídas entre 1으, 2으 e 3 은 trimestres e a partir dos dados coletados os resultados foram calculados da seguinte maneira: As notas do 20 trimestre foi comparada com as notas do 10 trimestre e as notas do 3 o trimestre comparadas com as notas do 2 ㅇ trimestre; A contagem das quantidades de notas aumentadas ou mantidas foram consideradas como positivas e as notas diminuídas consideradas como negativas. No caso do 5 o ano foi percebida uma melhora do desempenho escolar na disciplina de matemática de $86 \%$ entre o 1ํ e 2 ㅇ trimestres e $52 \%$ entre 20 e 3ำ trimestres, em ciências o resultado foi de $77 \%$ melhor entre o 10 e 2 o trimestres e $86 \%$ entre o 2 o e 3 o trimestres. № 60 ano foi percebida uma melhora na disciplina de matemática de $84 \%$ entre o 1ㅇ e 20 trimestres e $45 \%$ entre 20 e 3 은 trimestres, na disciplina de ciências o resultado foi de $84 \%$ melhor entre o $1^{\circ}$ e e $2^{\circ}$ trimestres e $67 \%$ entre o 2ㅇ e 3을 trimestres (GUARDA et al., 2018).

Em outro estudo realizado pelos autores Amaral et al. (2017) os mesmos realizaram a implementação de uma ferramenta em forma de um Portal Web para ajudar o professor no ensino de disciplinas iniciais em programação e esta ferramenta poderia ser utilizada pelos próprios alunos de forma individual para sua própria aprendizagem ou reforço na sua lógica programação, esta ferramenta foi chamada de Portal Algo+.

Nesta ferramenta o professor pode criar turmas e colaborar com o repositório de questões, já o aluno 
por sua vez pode se matricular em alguma das turmas disponíveis e essa matricula é validada pelo professor que criou a turma e após isso o conteúdo e as avaliações do modulo seriam disponibilizados ao aluno (AMARAL et al., 2017).

A ferramenta tem um sistema no qual o professor poderia acompanhar o registro de atividade dos alunos a fim de verificar seu desempenho e evolução dentro do ambiente. Também como citado anteriormente o professor pode cadastrar turmas para os alunos se inscreverem e nessas turmas poderiam ser vinculados a dois diferentes perfis sendo que em um deles os alunos estudam apenas uma linguagem de programação tradicional e no outro são estudados diferentes paradigmas. De acordo com o perfil selecionado para o aluno os conteúdos do portal são selecionados de forma dinâmica e exibidos para o aluno conforme seu avanço pelo módulo. Os conteúdos usados no portal Algo+ para construção do conhecimento em lógica de programação englobaram alguns paradigmas distintos estando entre eles a programação com blocos virtuais (Scratch), desenvolvimento para dispositivos móveis (Applnventor) e um paradigma de programação estruturada tradicional (Linguagem de programação C) (AMARAL et al., 2017).

A ferramenta implementada pelos autores deveria permitir aos alunos que eles tivessem autonomia no desenvolvimento de seus estudos e para isso o portal disponibiliza algumas ferramentas para atender os estudantes, essas ferramentas ficaram expostas em formas de 'abas' dentro do portal e são elas: Introdução e contextualização do Módulo; Downloads (onde o aluno poderia baixar alguns materiais de apoio); Material Teórico (conteúdo específico para leitura); Multimídia (vídeos e áudios que são relacionados ao Módulo atual); Atividades Formativas (exercícios com feedback automático); Atividade Avaliativa com 10 questões sendo que as questões que compõem a atividade são cadastradas pelos professores no sistema e aleatoriamente selecionadas para o aluno responder de acordo com seu módulo para que dessa forma cada avaliação possa ser considerada única e diferente das outras (AMARAL et al., 2017).

Para poder verificar se o portal Algo+ realmente seria efetivo no processo de ensino-aprendizagem de algoritmos e lógica de programação os autores convidaram dois professores da disciplina Algoritmos para utilizar essa ferramenta como um instrumento de apoio as suas aulas. Para estes professores foram disponibilizados os dois primeiros módulos de conteúdo do portal e estes módulos abrangem os conceitos de lógica de programação, construção de algoritmos, uso de variáveis e formas de representação de algoritmos (AMARAL et al., 2017).

O experimento foi realizado com duas turmas da disciplina de Algoritmos e Programação, sendo chamadas de turma A e turma B, a turma A era composta de 31 alunos do curso de Engenharia de Computação, e a turma B composta 16 alunos dos cursos de Engenharia de Produção, Engenharia de Alimentos, Engenharia de Energias e Física, assim somando um total 47 alunos. Os discentes puderam acessar o ambiente por duas semanas tendo o prazo de 7 dias para poder realizarem as atividades de cada módulo e dentro do portal eles tiveram acesso aos materiais introdutórios, indicações de leitura, recursos multimídia e atividades formativas (feedback automático). Quando o aluno chega ao final do módulo ele é submetido a uma atividade avaliativa composta por 10 questões e estas após respondidas resultados na aprovação ou não do aluno no módulo (AMARAL et al., 2017). 
Para poder avaliar os resultados da experiência realizada com o portal Algo+ os autores analisaram dois conjuntos de informações coletadas e eles são as notas/médias dos alunos ao utilizar os módulos do portal comparadas com as notas/médias em sala de aula e também foi realizada uma pesquisa em forma de questionário que foi respondida pelos alunos ao fim do segundo módulo (AMARAL et al., 2017).

Ao realizar a análise dos resultados do desempenho dos alunos participantes da experiência através de um estudo quantitativo os autores tiveram como base as notas obtidas no portal Algo+ em comparação com as notas obtidas em sala de aula, os autores também destacam que para a avaliação em sala de aula foram utilizadas as notas obtidas na primeira avaliação da disciplina que completava o conteúdo dos módulos abordados no portal Algo+. Os resultados do estudo foram que na turma A, a média das notas no portal Algo+ foi de 7,52 pontos enquanto em sala de aula foi de 7,85 pontos. Já na turma B os resultados foram que no portal Algo+ os alunos atingiram a meta de 6,69 pontos e em sala de aula a média foi de 6,29 pontos. Realizando uma comparação da média geral de ambas as turmas a nota foi de 7,10 no portal Algo+e 7,07 na sala de aula (AMARAL et al., 2017).

Para os autores do estudo o fato de que as médias dos alunos praticamente não se diferenciam pode ser considerado um fato positivo pois como os alunos tiveram vários recursos disponibilizados no portal, com a organização e alinhamento com as estratégias de ensino-aprendizagem conseguiram permitir que o aluno pudesse estudar de forma autônoma sem necessitar naquele momento de um tutoria direta de um professor, assim conseguindo obter um desempenho muito semelhando ao que foi conseguido direto em sala de aula (AMARAL et al., 2017).

Logo após ser analisado o desempenho dos alunos foi realizada a análise do questionário respondido pelos estudantes, foram respondidas ao todo pelos mesmos um total de 27 questões (abertas e fechadas) e no total 36 alunos responderam ao questionário. Os autores destacaram 4 perguntas que consideraram mais relevantes. A primeira pergunta questionava a organização dos conteúdos disponibilizados no portal e $86 \%$ dos alunos (31) responderam que a ordem dos conteúdos está interessante, 8\% dos alunos disseram ser indiferentes e $6 \%$ informaram que poderia ser diferente. Também foi questionado se a forma como os conteúdos estão disponibilizados estimulam nas atividades de estudo e $75 \%$ dos alunos (27) concordaram que sim, 14\% informaram indiferença e 11\% discordaram. Outra questão colocada foi saber se os conteúdos dos módulos permitiram que o aluno, ao passar para o próximo módulo, tivesse uma base suficiente dos conteúdos do módulo anterior para pode continuar o estudo dos novos conteúdos apresentados e nessa questão $100 \%$ dos alunos responderam que sim. Por último foi questionado aos alunos tendo em vista toda a experiência que tiveram na utilização do portal de indicariam essa ferramenta para seus colegas e 34 dos 36 estudantes responderam que sim, indicando assim que a ferramenta poderia realmente ter potencial para apoio ao processo de aprendizagem de algoritmos (AMARAL et al., 2017).

\section{CONCLUSÕES}

Neste trabalho foi possível observar, de acordo com experimentos já realizados anteriormente por outros autores, as ferramentas tecnológicas têm muito a oferecer quando se fala em metodologia de ensino 
e através do uso desta, pode-se despertar maior interesse por partes de estudantes para o aprendizado de novos conteúdos. Segundo as obras selecionadas para este estudo, os resultados dos experimentos analisados podem ser considerados promissores e deixa claro que há novas e variadas possibilidades em relação a métodos de ensino quando há o uso de ferramentas tecnológicas para tal fim.

Quando se fala em usar ferramentas tecnológicas logo se pensa no uso de computadores, smartphones ou eletrônicos afins, porém nem todo caso é necessário ou viável, como demonstrado nesse artigo através do experimento das autoras Guarda et al. (2018), as ferramentas tecnológicas podem também ser adaptadas, para nossa realidade de acordo com aquilo que nós podemos fazer e mesmo assim conseguir ter bons resultados usando materiais simples disponíveis em praticamente qualquer lugar. O que se faz realmente necessário é se pensar em uma boa metodologia para o uso dessas ferramentas, assim é possível despertar e motivar o interesse daqueles que precisam e querem, aprender de forma mais dinâmica e eficiente, assim como demonstraram os autores Amaral et al. (2017).

Enfim, pode-se considerar que as ferramentas tecnológicas podem e devem ser usadas como um método inovador e eficiente para novas metodologias de ensino-aprendizagem, contanto que a metodologia de aplicação dessas ferramentas tenha um bom planejamento de viabilidade, tanto econômica quanto da observação das necessidades daqueles que estarão inseridos na aprendizagem dos conteúdos e assim facilitar o processo de ensino educacional trazendo melhores resultados.

\section{REFERÊNCIAS}

AMARAL, E.; CAMARGO, A.; GOMES, M.; RICHA, C. H.; BECKER, L.. ALGO+ Uma ferramenta para o apoio ao ensino de Algoritmos e Programação para alunos iniciantes. In: SIMPÓSIO BRASILEIRO DE INFORMÁTICA NA EDUCAÇÃO. Anais. SBIE, 2017. p.1677. DOI: http://dx.doi.org/10.5753/cbie.sbie.2017.1677

DIAS, E. J. P.; ARRUDA FILHO, E. J. M.. Comportamento do consumidor no setor educacional: adoção e aceitação de novas tecnologias. Revista Pretexto, Belo Horizonte, v.14, n.2, p.77-95, 2013.

FERNANDES, J. C. L.. Educação digital: Utilização dos jogos de computador como ferramenta de auxílio à aprendizagem. Fasci-Tech, São Caetano do Sul, v.1, n.3, p.88-97, 2010.

FERREIRA, J. A. G.; SCHRÖEDER, C. S.. Educação a Distância: Um Estudo da Mudança Organizacional no Processo Inicial de Implantação da Modalidade em uma Instituição de Ensino Superior Privada. Revista de Administração IMED,
Passo Fundo, v.7, n.1, p.49-69, 2017. DOI: https://doi.org/10.18256/2237-7956/raimed.v7n1p49-69

GUARDA, G.; GOULART, I.. Jogos Lúdicos sob a ótica do Pensamento Computacional: Experiências do Projeto Logicamente. In: SIMPÓSIO BRASILEIRO DE INFORMÁTICA NA EDUCAÇÃO. Anais. SBIE, 2018. p.486. DOI: http://dx.doi.org/10.5753/cbie.sbie.2018.486

LOZADA, G.; NUNES, K. S.. Metodologia científica. Porto Alegre: SAGAH, 2018.

MARTINS, M.; FARIAS, J. S.; ALBUQUERQUE, P. H. M.; PEREIRA, D. S.. Adoção de Tecnologia para Fins de Leitura: Um Estudo da Aceitação de E-Books. BBR, Braz. Bus. Rev., Vitória, v.15, n.6, p.568-588, 2018. DOI: https://doi.org/10.15728/bbr.2018.15.6.4

QUINTANA, A. C.; AFONSO, L. E.. Tecnologias na educação: há impacto no desempenho acadêmico?. Revista Universo Contábil, v.14, n.1, p.7-28, 2018. DOI: http://doi:10.4270/ruc.2018101

A CBPC - Companhia Brasileira de Produção Científica (CNPJ: 11.221.422/0001-03) detém os direitos materiais desta publicação. Os direitos referem-se à publicação do trabalho em qualquer parte do mundo, incluindo os direitos às renovações, expansões e disseminações da contribuição, bem como outros direitos subsidiários. Todos os trabalhos publicados eletronicamente poderão posteriormente ser publicados em coletâneas impressas sob coordenação da Sustenere Publishing, da Companhia Brasileira de Produção Científica e seus parceiros autorizados. Os (as) autores (as) preservam os direitos autorais, mas não têm permissão para a publicação da contribuição em outro meio, impresso ou digital, em português ou em tradução. 